\title{
Grey Correlation Analysis and Grey Prediction Based on the GDP and Each Industrial added Value of Sichuan Province
}

\author{
Changwei Xiong $^{1, a}$, Yi Zhang ${ }^{2, b}$
}

1. Statistical Bureau of Nanchong 637000, China

2. College of Mathematics and information institute, China West Normal University, Nanchong 637009, China

aemail:25638250@QQ.com bemail: 12782468@QQ.com

Key words: GDP; grey relational analysis; grey GM (1.1) model; prediction

Abstract: In this paper, the grey correlation analysis is used to analyze the influence of each industry added value on GDP of Sichuan province. The GDP, the first, second and third industry added value of Sichuan data in 2005-2012 is analyzed. The grey GM (1.1) model is used to establish a forecasting model for the four kinds of data, to get higher accuracy.

\section{Introduction}

In order to make a detailed analysis of the GDP in Sichuan Province, we make a quantitative analysis of the impact of the first, second and third industry added value on the region's GDP, and get the sort of their impact on the GDP. So, we establish the forecast model for GDP, the first, second and third industries in Sichuan province, and forecast their short-term development trend.

\section{Grey correlation analysis}

In order to analyze the influence degree and correlation degree of the first, second and third industrial added value on the GDP in Sichuan Province, according to the characteristics of "small sample and poor information", we use grey correlation analysis to study the influence of the three industry added value on the GDP in Sichuan Province.

Definition 1[1]: If $x_{0}=\left(x_{(0)}(1), x_{(0)}(2), \cdots, x_{(0)}(n)\right)$ is the system behavior characteristic sequence, $\quad x_{i}=\left(x_{(i)}(1), x_{(i)}(2), \cdots, x_{(i)}(n)\right)$ is the related factor sequences, then said $\Delta_{i}(k)=\left|x_{0}(k)-x_{i}(k)\right| \quad(k=1,2, \cdots, n)$ is the difference sequences.

Definition 2[1]: Said $r\left(x_{0}(k), x_{i}(k)\right)=r_{i}(k)$ is $x_{i}$ for $x_{0}$ in the $\mathrm{K}$ point of the grey correlation $r_{i}(k)=\frac{\operatorname{li}_{i}}{\Delta_{i}(k)+\rho \max _{i} \max _{k} \Delta_{i}(k)} \quad \rho \in[0,1]$
coefficient. Among them, Definition 3[2]: Said $r\left(x_{0}, x_{i}\right)=r_{i}$ is $x_{i}$ for $x_{0}$ grey correlation degree, among them $r_{i}=\frac{1}{n} \sum_{k=1}^{n} r_{i}(k)$

We take 2005-2012 Sichuan province GDP [3] for the system behavior characteristics of the sequence, the added value of the first, second and third industry data sequence for related factors. Using MATLAB software to calculate the grey correlation coefficient of the first, second and third industrial added value series [4,5]:

$\mathrm{r}_{1}(k)=(0.9020,0.8402,0.7761,0.7065,0.6580,0.5845,0.5155,0.4732)$

$\mathrm{r}_{2}(\mathrm{k})=(1,0.9607,0.9015,0.8559,0.8239,0.7769,0.7200,0.6691)$

$r_{3}(k)=(0.9845,0.9328,0.8607,0.7969,0.7591,0.6811,0.6010,0.5635)$

the added values of the three industrial to GDP of Sichuan province of grey correlation degree are:

$r_{1}=0.6820, \quad r_{2}=0.8385, \quad r_{3}=0.7725$ 
According to the grey relational degree, the first, second and third industrial added value of Sichuan Province, the correlation degree of province from big to small sort: the second industry, the third industry, the first industry, namely: the second industry has the greatest impact on the GDP of Sichuan Province, the first industry has the least impact. Because of the difference of the value of the three grey related degrees, the industrial structure of Sichuan province is constantly improving and optimizing, but the three major industries are not dominant.

\section{Prediction of GDP, the first, second and third industry added value of Sichuan Province}

According to the National Statistical Yearbook in 2005 - 2012 Sichuan Province GDP , the first, second and third industrial added value data , this article argues that Mr. Deng Ju-long used GM (1, 1) model to predict can obtain higher accuracy. Deng Ju-long proposed GM $(1,1)$ model, its application in many fields, the characteristics of the sample is less, and the calculation is simple, so it is better than the traditional forecasting method.

Theorem: let $x^{(0)}$ be a non-negative quasi smooth sequence, $x^{(0)}=\left\{x^{(0)}(1), x^{(0)}(2), \cdots, x^{(0)}(n)\right\}$, $x^{(1)}=\left\{x^{(1)}(1), x^{(1)}(2), \cdots, x^{(1)}(n)\right\}$ is the 1-AGO sequence of $x^{(0)}$ (among them: $x^{(1)}(k)=\sum_{i=1}^{k} x^{(0)}(i)$ ), $z^{(1)}=\left\{z^{(1)}(2), z^{(1)}(3), \cdots, z^{(1)}(n)\right\} \quad$ is the immediately mean sequence of $x^{(1)}$ (among them: $\quad z^{(1)}(k)=\frac{1}{2}\left(x^{(1)}(k)+x^{(1)}(k-1)\right) \quad$ )if $\quad \alpha=(a, b)^{T} \quad$ is parameters, then $x^{(0)}(k)+a z^{(1)}(k)=b \quad k=2,3, \ldots \quad$ is grey differential equation GM $(1,1)$ model, $\quad \frac{d x^{(1)}}{d t}+a x^{(1)}=b$ is the whitening differential equation of GM $(1,1)$ model .Set $Y=\left(\begin{array}{c}x^{(0)}(2) \\ x^{(0)}(3) \\ \vdots \\ x^{(0)}(n)\end{array}\right), \quad B=\left(\begin{array}{cc}-z^{(1)}(2) & 1 \\ -z^{(1)}(3) & 1 \\ \vdots & \vdots \\ -z^{(1)}(n) & 1\end{array}\right)$ then:1) $\alpha=(a, b)^{T}$ can be obtained by the least square method: $\hat{\alpha}=\left(B^{T} B\right)^{-1} B^{T} Y$

2)The continuous solution of differential equation is:

$$
x^{(1)}(k)=\left(x^{(1)}(1)-\frac{b}{a}\right) e^{-a(k-1)}+\frac{b}{a}
$$

3)The discrete solution of differential equation is:

$$
x^{(1)}(k)=\left(x^{(1)}(1)-\frac{b}{a}\right) e^{-a(k-1)}+\frac{b}{a} \quad k=2,3, \ldots
$$

4)Reduction value: $\hat{x}^{(0)}(k+1)=\hat{x}^{(1)}(k+1)-\hat{x}^{(1)}(k) \quad k=1,2, \ldots$

The GM (1,1) models we set up on 2005 - 2012 in Sichuan province GDP, the first, second and third industrial added value data by MATLAB are as follows[6,7]:

Sichuan province GDP: $\quad x^{(1)}(k)=48348.73547 e^{0.167401(k-1)}-40963.6354 \quad k=2,3, \ldots$

the first industrial added value: $x^{(1)}(k)=14615.4464 e^{0.109401(k-1)}-13134.3064 \quad k=2,3, \ldots$

the second industrial added value: $x^{(1)}(k)=17592.9865 e^{0.198222(k-1)}-14525.7565 \quad k=2,3, \ldots$

the third industrial added value: $x^{(1)}(k)=20564.7644 e^{0.149805(k-1)}-17728.0344 \quad k=2,3, \ldots$

According to the above models, the fitting values and relative errors are obtained, they are shown in Table 1 and Table 2. 
Table 1: the fitting value and relative error of GDP and the first industry of Sichuan

\begin{tabular}{|c|c|c|c|c|c|c|}
\hline year & GDP & $\begin{array}{c}\text { Fitted } \\
\text { values }\end{array}$ & $\begin{array}{c}\text { Relative } \\
\text { error }(\%)\end{array}$ & $\begin{array}{c}\text { The first } \\
\text { industry }\end{array}$ & $\begin{array}{c}\text { Fitted } \\
\text { values }\end{array}$ & $\begin{array}{c}\text { Relative } \\
\text { error }(\%)\end{array}$ \\
\hline 2005 & 7385.1 & & & 1481.14 & & \\
\hline 2006 & 8690.24 & 8810.5 & -1.38 & 1595.48 & 1689.69 & -5.9 \\
\hline 2007 & 10562.39 & 10416.02 & 1.39 & 2032 & 1885.03 & 7.23 \\
\hline 2008 & 12601.23 & 12314.12 & 2.28 & 2216.15 & 2102.96 & 5.11 \\
\hline 2009 & 14151.28 & 14558.09 & -2.87 & 2240.61 & 2346.08 & -4.71 \\
\hline 2010 & 17185.48 & 17210.99 & -0.15 & 2482.89 & 2617.32 & -5.41 \\
\hline 2011 & 21026.68 & 20347.31 & 3.23 & 2983.51 & 2919.9 & 2.13 \\
\hline 2012 & 23872.8 & 24055.16 & -0.76 & 3297.21 & 3257.47 & 1.21 \\
\hline 2013 & & 28438.69 & & & 3634.07 & \\
\hline 2014 & & 33621.02 & & & 4054.21 & \\
\hline
\end{tabular}

Table 2: the fitting value and relative error of the second and third industry of Sichuan

\begin{tabular}{|c|c|c|c|c|c|c|}
\hline year & $\begin{array}{c}\text { The second } \\
\text { industry }\end{array}$ & $\begin{array}{c}\text { Fitted } \\
\text { values }\end{array}$ & $\begin{array}{c}\text { Relative } \\
\text { error }(\%)\end{array}$ & $\begin{array}{c}\text { The third } \\
\text { industry }\end{array}$ & $\begin{array}{c}\text { Fitted } \\
\text { values }\end{array}$ & $\begin{array}{c}\text { Relative } \\
\text { error (\%) }\end{array}$ \\
\hline 2005 & 3067.23 & & & 2836.73 & & \\
\hline 2006 & 3775.14 & 3856.97 & -2.17 & 3319.62 & 3323.43 & -0.11 \\
\hline 2007 & 4648.79 & 4702.54 & -1.16 & 3881.6 & 3860.52 & 0.54 \\
\hline 2008 & 5823.39 & 5733.50 & 1.54 & 4561.69 & 4484.41 & 1.69 \\
\hline 2009 & 6711.87 & 6990.47 & -4.15 & 5198.8 & 5209.13 & -0.2 \\
\hline 2010 & 8672.18 & 8523.02 & 1.72 & 6030.41 & 6050.97 & -0.34 \\
\hline 2011 & 11029.13 & 10391.55 & 5.78 & 7014.04 & 7028.85 & -0.21 \\
\hline 2012 & 12333.28 & 12669.73 & -2.73 & 8242.31 & 8164.77 & 0.94 \\
\hline 2013 & & 15447.36 & & & 9484.27 & \\
\hline 2014 & & 18833.94 & & & 11017 & \\
\hline
\end{tabular}

From table 1- table 2: the fitting effect of the grey GM $(1,1)$ model is good, and the fitting accuracy of the four models are: $98.28 \%, 95.47 \%, 97.25 \%, 99.42 \%$, Can be seen, the fitting accuracy of the four models are more than $95 \%$, We use the grey GM $(1,1)$ model to establish the model of the four groups of data is valid and feasible. Thus, we use these four models respectively for 2013, 2014 in Sichuan province GDP, the first, two or three industry added value have been predicted: 2013 they were: 28438.69 Billion, 3634.07 Billion, 15447.36 Billion, 9484.27 Billion; 2014 they were: 33621.02 Billion, 4054.21 Billion, 18833.94 Billion and 11017.00 Billion. Thus, Sichuan GDP, the first, two or three industry increase in the next few years are still showing a larger growth trend, the rapid development of the second industry, in the next two years, the contribution of GDP in Sichuan Province, the first and third industry growth rate is relatively backward in the second industry.

\section{Acknowledgements:}

Funded projects: China West Normal University Fund (14D015). 
Corresponding author: Yi Zhang (1982- ), female, Nanchong, Associate Professor of Mathematics and Information China West Normal University, is mainly engaged in the theoretical study of grey system.

\section{References}

[1] Julong Deng, grey prediction and grey decision [M], Wuhan: press of Huazhong University of Science and Technology, 2002

[2] Sifeng Liu, Yaoguo Dang, Zhigeng Fang, grey system theory and its application [M] Beijing: Science Press, 2004

[3]China Statistical Yearbook[EB/OL], http://data.stats.gov.cn/workspace/index?m=fsnd.

[4] Linyuan Wang, Xi Li, grey model in GDP of Jiangxi province (GDP) application and analysis [J], Journal of Nanchang University (NATURAL SCIENCE EDITION), 2006, Vol.30, No.5, P452-454

[5] Min Li, Yang Wang, The application of GM $(1,1)$ model to forecast the gross product of Chengdu City [J], Journal of Foshan University (NATURAL SCIENCE EDITION), 2011, No.5, P32-34., Vol.29.

[6] Qun Li, Chenguang Pan, High accuracy grey model research and forecast of 2005 GDP [J], financial issues research, 2005, eighth (total 261st), P11-13.

[7] Yi Zhang, Yong Wei, Changwei Xiong. A new optimization method for grey model GM $(1,1)$ [J], system engineering theory and practice, 2007, 4:P141-146. 